by Milne, then shows that the space-time is stratified in such a way that the line element may be written in the form

$d s^{2}=d t^{2}-c^{-2} e^{g(t)}\left\{\left(1-k r^{2} / R_{0}{ }^{2}\right) d r^{2}+r^{2} d \theta^{2}+r^{2} \sin ^{2} \theta d \dot{\varphi}^{2}\right\}$,

where the world-lines of nebulæ $(r, \theta, \varphi=$ constants) are orthogonal to the hyper-surfaces of stratification $S, t=$ constant. The general theory provides an expression for $g(t)$ in terms of the cosmological constant $\lambda$, the curvature constant $k$ of the hypersurfaces $S$ (which may be $+1,0$, or -1, ) the radius $R_{0}$ of $S$, and the number $\alpha$ of nebulæ per unit volume on some specified $S$. Prof. Temple concluded by directing attention to the fact that the system of real co-ordinates $(t, r, \theta, \varphi)$ covers only that region of space-time actually traversed by the nebulæ, and he indicated the possibility that an empty region of space time might exist outside the system of expanding nebulæ - as it actually does in Milne's theory.

Dr. MeVittie then gave a critical account of the construction of the semi-empirical equations summarizing the observed relations between the red-shift $\delta$, the apparent photographic magnitude $m$ and the number $N_{m}$ of nebulæ with magnitudes less than $m$. He pointed out that Hubble's equations depend upon a number of ad hoc assumptions which are entirely arbitrary in character and unsupported by the general relativistic theory. In these circumstances, the obvious course is to utilize the relations between observable quantities furnished by the general theory. These alone, however, are insufficient and an additional datum is required, which McVittie finds in the estimate of the average mass of the visible nebulæ, $M_{0}=4 \times 10^{44} \mathrm{gm}$. His analysis of the observations leads to the surprising conclusion that $k=-1$, so that the hyper-surfaces $S$ are 'hyperbolic' in character, the radius $R_{0}$ lying between $10^{8}$ and $10^{9}$ parsecs. The average density is probably of the order of $10^{-29} \mathrm{gm} . \mathrm{cm} .^{-3}$ and the effective temperature of the nebular radiation lies between $5,000^{\circ}$ and $7,500^{\circ}$. The cosmical constant $\lambda$ is expressed by the difference of two numbers of the same order of magnitude, and, owing to the considerable uncertainty in their values, no reliable information is forthcoming concerning the value of $\lambda$.

In the subsequent discussion, an important point was raised by Sir James Jeans, who inquired if the sign of $k$ is sensitive to changes in the estimation of the average nebular mass $M$. In reply, Dr. McVittie stated that the conclusion $k=-1$ would probably persist even if his estimated value of $M_{0}$ were increased by a factor of about 50 .

Sir Arthur Eddington stressed the importance of basing cosmological investigations upon a standard of length which would be accepted not only in relativity, but also in quantum theory and in metrology. Since such a standard can only be specified in terms of dimensionless numbers, it would necessarily be a structure with definite quantum numbers or composed of a definite number of atoms, as, for example, $10^{8}$ lattice spaces of calcite. Finally, he stressed that theoretical cosmology is a normal and natural extension of well-known physical principles and deplored the mystery with which this subject is sometimes cloaked.

Prof. W. H. McCrea referred to recent nebular counts by Shapley which appear to indicate that the distribution is not isotropic, and he showed by a very simple argument that Hubble's velocity-distance relation would still remain true in any assigned direction. The Astronomer Royal also referred to the lack of homogeneity revealed in Shapley's observations, and appealed to mathematicians to develop a. more general theory capable of dealing with this more complex situation. Dr. McVittie in replying to these comments stated that in his very latest paper Shapley admitted that his former conclusion is rendered uncertain by an error of calibration, but he believes that when the correct calibration is completed, there will still remain some lack of isotropy in the nebular distribution.

Prof. W. Wilson stated that in spite of its simplicity, Milne's cosmological theory suffers from the defect that it does not incorporate detailed gravitational phenomena such as planetary motions. On the other hand, he felt that in the domain of general relativity the early simple theory of de Sitter may be an adequate expression of the facts. Prof. Temple said in reply that the de Sitter universe is in fact the ultimate state of all the continually expanding models proposed by general relativity.

1 Rev. Mod. Phy8., 5, 62.

\title{
A Congress of Aeronautical Geography
}

\begin{abstract}
THAT there are relations between geography and 1 aviation was officially acknowledged, so to speak, for the first time in the week of November 28December 3, when the First Congress of Aeronautical Geography (Premier Congrès de Géographie Aérienne) was held in Paris under the auspices of the French Ministers for Air and National Education. It had been organized by the Union Syndicale des Industries Aéronautiques (not by a geographical body), the vicepresident of which, General Duval, acted as chairman, and eminent representatives of French science and aviation served as chairmen of various sessions. Twenty-two papers were read, dealing with the different aspects of aviation so far as they may be of interest to the geographer.
\end{abstract}

The programme commenced with two meteorological papers, read by Messrs. G. Dedebant and A. Viaut, of the French National Meteorological Office, and an excellent discourse on the international regulation of eivil aviation, given by Dr. A. Roper, secretarygeneral of the International Commission for Aerial Navigation. M. R. Bureau, of the Meteorological Office, discussed the stratosphere, and the well-known pre-War pilot and aeronautical inventor, M. R. Esnault-Pelterie, spoke on interplanetary space. A number of papers dealt with the geographical and economic conditions and the statistical results of commercial aviation in general (M. J. Vivent, sub-director of civil aeronautics in the Air Ministry) and of different long-distance air-lines (Messrs. R. Perret, vice-president of the Association des Géographes Francais: line France-Madagascar of Régie Air-Afrique; Prof. J. Martin : lines France-South America and France-Indochina of Cie. Air-France; Prof. J. Weulersse : line London-Capetown of Imperial Airways Ltd.; F. Ruellan, director of studies: line Amsterdam-Batavia. 
of Koninklijke Luchtvaart Mij.; Prof. E. Dennery : line New York-San Francisco of United Air Lines, Inc.). The services which aviation is able to render to geography and allied sciences were discussed by the following : M. A. Carlier, manager of the Société Générale de Photo-Topography (on aerial photography) ; Prof. P. George (on the role of aviation in the exploration of the polar regions); Father Poidebard (on the exploration of ancient civilizations by aeroplane) ; Prof. A. Demangeon (on the investigation of agricultural systems from the air); M. F. Blondel, chief mining engineer (how to employ the aeroplane for geological investigations and for prospecting); Prof. E. de Martonne (on the contribution of aviation to morphological studies); M. G. Huisman, directorgeneral of Fine Arts (on the aid of aviation in studying and conserving the architectonic treasures of France). There was also an interesting causerie by the well-known airman, M. P. Codos, on transcontinental and trans-oceanic flights. A number of other papers were of a more technical character.

It is to be regretted that the attendance at the Congress was not large; the date of the meeting had been chosen with regard to the sixteenth International Aeronautical Exhibition held at the Grand Palais des Champs-Elysées, but it is obviously not very convenient for a scientific congress. Though the meeting had been intended to be an international one, the speakers were, without a single exception, French, and nearly the same is true of the hearers, among whom there were only half a dozen foreigners. It is to be hoped that the next Congress of Aeronautical Geography, which will be held in 1940, again in Paris, may have larger and more international support.

Carl Hanns Pollog.

\section{The Testing of Electrical Switchgear}

$\mathrm{T}$ HE Department of Scientific and Industrial Research stated last year that at the request of a number of manufacturers of switchgear, it was considering the establishment of a short-circuit testing station at the National Physical Laboratory which would be capable of testing switchgear specified to be able to break a circuit having a current $I$ flowing in it with a possible maximum voltage $V$ across the gap of the circuit breaker, when the product of $V$ and $I$ is 250 million volt-amperes, certain limitations being made as to the value of $V$ and $I$. The cost of such a laboratory would be very high, as it would have to be built at an appreciable distance from other laboratories and it would have to generate its own power. Only a limited number of full-scale tests could be made per annum and so it would need a large Government grant.

The Department, therefore, issued a questionnaire to interested firms and bodies, inviting their views on various aspects of the proposal and on certain tentative proposals by means of which the National Physical Laboratory might be able to issue certificates that the gear has successfully passed certain specified tests. The replies disclosed a considerable measure of agreement. It was desirable to provide testing facilities which would be available for those manufacturers who did not possess testing stations, and that it should also be possible for such manufacturers to obtain certificates issued by an independent body in respect of such tests. At the same time, those companies which have already erected short-circuit testing stations for their own use indicated some doubt as to whether additional testing capacity in Great Britain was justified as there were already in existence greater testing facilities than are available in any other country in which switchgear is produced. They pointed out that they had spare capacity available. They offered to assist the Department in exploring the proposal further by supplying information from their own experience. As the result of most friendly discussions with the Department, it appeared possible to collaborate with the owners of existing short-circuit testing stations and so provide facilities in those stations for testing for any British manufacturer. Negotiations to this end began in 1937.
Agreement has been recently reached on a scheme which it is hoped will be adequate to meet requirements. This scheme permits the existing testing stations to continue to issue their own certificates, and in addition provides facilities for the issue of N.P.L. certificates when required in respect of circuit breakers coming within the agreed range which attain a standard of performance defined in the appropriate British Standards specification. The negotiations were made much easier by the fact that the owners of existing stations had already taken preliminary steps to co-ordinate their work and had provisionally decided to form an 'Association of Short-Circuit Testing Authorities' which would act as a testing or certifying body. This Association is now being incorporated. The main features of the new scheme are as follows. Owners of testing stations will provide facilities to any British manufacturer, without distinction, and will undertake that the fulltime use of one test bay will be made available collectively, by the existing testing plants, for tests for those manufacturers who do not themselves own testing stations. Tests will be normally carried out to the requirements of a definite British Standards specification. While the Association of Short-Circuit Testing Authorities will issue its own certificates of rating and records of performance, it will be possible to obtain N.P.I. certificates. Application for N.P.L. certificates under the arrangements should be addressed to the Director, National Physical Laboratory, who will decide at which station any individual test can be made. Strict confidence will be observed in connexion with the design of circuit-breakers submitted for test.

The stations at present included in the scheme are those of : The English Electric Co., Ltd., the General Electric Co., Ltd., the Switching Testing Co., Ltd., Trafford Park, which is jointly owned by the British Thomson-Houston Co., Ltd., Messrs. Ferguson Pailin, Ltd., and the Metropolitan-Vickers Electrical Co., Ltd.; The British Short-Circuit Testing Station, Ltd., Hebburn-on-Tyne, owned by Messrs. A. Reyrolle and Co., Ltd. As soon as the National Physical Laboratory is ready to receive orders for tests, leaflets giving full details of the arrangements for tests, including particulars of charges, will be available. 